\title{
Using a Nanoelectrospray-Differential Mobility Spectrometer-Mass Spectrometer System for the Analysis of Oligosaccharides with Solvent Selected Control Over ESI Aggregate Ion Formation
}

\author{
Daren S. Levin and Paul Vouros \\ Department of Chemistry and Chemical Biology and Barnett Institute of Chemical and Biological Analysis, \\ Northeastern University, Boston, Massachusetts, USA
}

\author{
Raanan A. Miller and Erkinjon G. Nazarov \\ Sionex Corporation, Bedford, Massachusetts, USA
}

\begin{abstract}
Differential mobility spectrometry (DMS), also commonly referred to as high field asymmetric waveform ion mobility spectrometry (FAIMS) is a rapidly advancing technology for gas-phase ion separation. The interfacing of DMS with mass spectrometry (MS) offers potential advantages over the use of mass spectrometry alone. Such advantages include improvements to mass spectral signal/noise, orthogonal/complementary ion separation to mass spectrometry, enhanced ion and complexation structural analysis, and the potential for rapid analyte quantitation. In this report, we demonstrate the successful use of our nanoESI-DMS-MS system, with a methanol drift gas modifier, for the separation of oligosaccharides. The tendency for ESI to form oligosaccharide aggregate ions and the negative impact this has on nanoESI-DMS-MS oligosaccharide analysis is described. In addition, we demonstrate the importance of sample solvent selection for controlling nanoESI oligosaccharide aggregate ion formation and its effect on glycan ionization and DMS separation. The successful use of a tetrachloroethane/methanol solvent solution to reduce ESI oligosaccharide aggregate ion formation while efficiently forming a dominant $\mathrm{MH}^{+}$molecular ion is presented. By reducing aggregate ion formation in favor of a dominant $\mathrm{MH}^{+}$ion, DMS selectivity and specificity is improved. In addition to DMS, we would expect the reduction in aggregate ion complexity to be beneficial to the analysis of oligosaccharides for other post-ESI separation techniques such as mass spectrometry and ion mobility. The solvent selected control over $\mathrm{MH}^{+}$molecular ion formation, offered by the use of the tetrachloroethane/methanol solvent, also holds promise for enhancing MS/MS structural characterization analysis of glycans. (J Am Soc Mass Spectrom 2007, 18, 502-511) (c) 2007 American Society for Mass Spectrometry
\end{abstract}

$\mathrm{D}$ ifferential mobility spectrometry (DMS) [1], also referred to as high field asymmetric waveform ion mobility spectrometry (FAIMS) [2], and field ion spectrometry (FIS) [3], is a rapidly advancing technology for gas-phase ion separation. DMS has the potential to emerge as a major stand-alone separation science technique such as LC or GC. Many researchers have focused on interfacing DMS to mass spectrometry because of its atmospheric pressure, gas-phase, continuous ion separation capabilities, and the detection specificity offered by mass spectrometry. In this study, we investigate the use of a specially designed

Published online November 30, 2006

Address reprint requests to Dr. P. Vouros, Department of Chemistry and Chemical Biology and Barnett Institute of Chemical and Biological Analysis, Northeastern University, Boston, MA 02115, USA. E-mail: p.vouros@ neu.edu
nanoESI-DMS-MS system for the analysis of oligosaccharides. Glycosylation of proteins has been demonstrated to play a significant role in their biological function [4-7]. Characterization of glycoprotein glycan groups is essential to understanding how they influence protein function [8-10]. ESI-MS has become a popular analysis platform for characterizing oligosaccharides because of its compatibility with up-stream separation techniques such as liquid chromatography and capillary electrophoresis, as well as the structure-rich information provided by $\mathrm{MS}^{\mathrm{n}}$ techniques [8-10]. In this study, we demonstrate the successful use of nanoESIDMS-MS with a methanol drift gas modifier for the separation of oligosaccharides. In addition, we demonstrate the importance of sample solvent selection in glycan cluster ion formation and its effects on glycan ionization and DMS separation. 
DMS is related to, but is fundamentally different, from conventional time-of-flight ion mobility spectrometry. In conventional ion mobility spectrometry, ion identification is related to effective ion cross section, resulting in differences in flight times. In DMS, ion identification is related to changes in effective cross section based on the propensity of the ion to cluster/ decluster, resulting in differences in applied compensation voltage values. In DMS, an asymmetric electric field waveform is applied to two parallel electrode plates enabling the ions to pass through in a continuous, nonpulsed manner. The electrical waveform consists of a high field duration of one polarity and then a low field duration of opposite polarity, such that the integrated voltage time being applied to the electrode is zero [11]. Figure 1 demonstrates the high and low voltages of opposite polarity applied to generate the asymmetric electrical waveform (identified as an $\mathrm{Rf}$ voltage, correlating to the high voltage value). As can be seen, after one cycle of the waveform the average voltage applied to the electrode is zero, however the ion's mobility in this asymmetric electric field displays a net movement towards the bottom (grounded) electrode plate. Since an ion may experience a net mobility towards one of the electrode plates during its travel between the plates, a compensation voltage $\left(V_{c}\right)$ is applied to maintain a safe trajectory through the plates without striking them. In this manner the DMS sensor acts as a tunable ion filter, where varying the applied waveform (Rf) and compensation voltages (Vc), allow for selective ion transmission through the sensor. In DMS ions are separated at pressures sufficient for the occurrence of collisions between ions and the neutral gas molecules. The smaller the ion, the fewer collisions it will experience as it is pulled through the drift gas. Because of this, ion cross sectional area plays a significant role in its mobility through the drift gas [11, 12].

ESI-MS analysis of oligosaccharides and glycans has become a powerful tool for both structural characterization and quantitation. Although ESI-MS is a popular choice for glycan analysis, poor ionization efficiency of many native glycan molecules in positive mode ESI has led researchers to investigate ways to improve glycan ionization [13-16]. Due to the poor basicity of glycans, formation of sufficient $\mathrm{MH}^{+}$ion abundance in positive mode ESI is difficult to achieve [13-16]. Negative mode ESI offers ionization advantages for the analysis of glycans, however, positive mode ESI is also desirable due to its capability to generate different MS/MS glycan ion fragmentation than typically observed in negative mode ESI-MS/MS [17, 18]. To improve positive mode ESI ionization of glycans, derivatization of glycans with molecules containing basic sites has been employed [19]. While this approach has been successful, it increases the complexity of sample preparation, such that many researchers have explored other means by which analysis of underivatized glycans can be performed in positive mode ESI [13, 17, 18, 21]. It has been found that metal and ammonium ion complexes, such as $\mathrm{MNa}^{+}$and $\mathrm{MNH}_{4}{ }^{+}$, form readily with contaminant/residual cations in the ESI solution [14, 20]. As a result, many of these glycan-cation complexes have been utilized as the molecular ions for analysis via the introduction of salts at low $\mathrm{mM}$ concentrations into the ESI solution to maintain consistent ionization efficiency and generate structurally informative MS/MS fragmentation patterns $[13,15-18,21-25]$. Harvey et al. reported that $\mathrm{MH}^{+}$glycan ions fragment differently than their $\mathrm{MNa}^{+}$and $\mathrm{MLi}^{+}$ion counterparts $[15,18]$. The MS/MS spectrum of the $\mathrm{MH}^{+}$ion was less complex and primarily made up of glycosidic cleavages, whereas the sodium and lithium adduct ions resulted in more complex MS/MS spectra with cross ring cleavages in addition to the glycosidic cleavages [15, 18].

Gabryelski et al. investigated the use of ESI-FAIMS-MS for oligosaccharide separation, and explored the addition
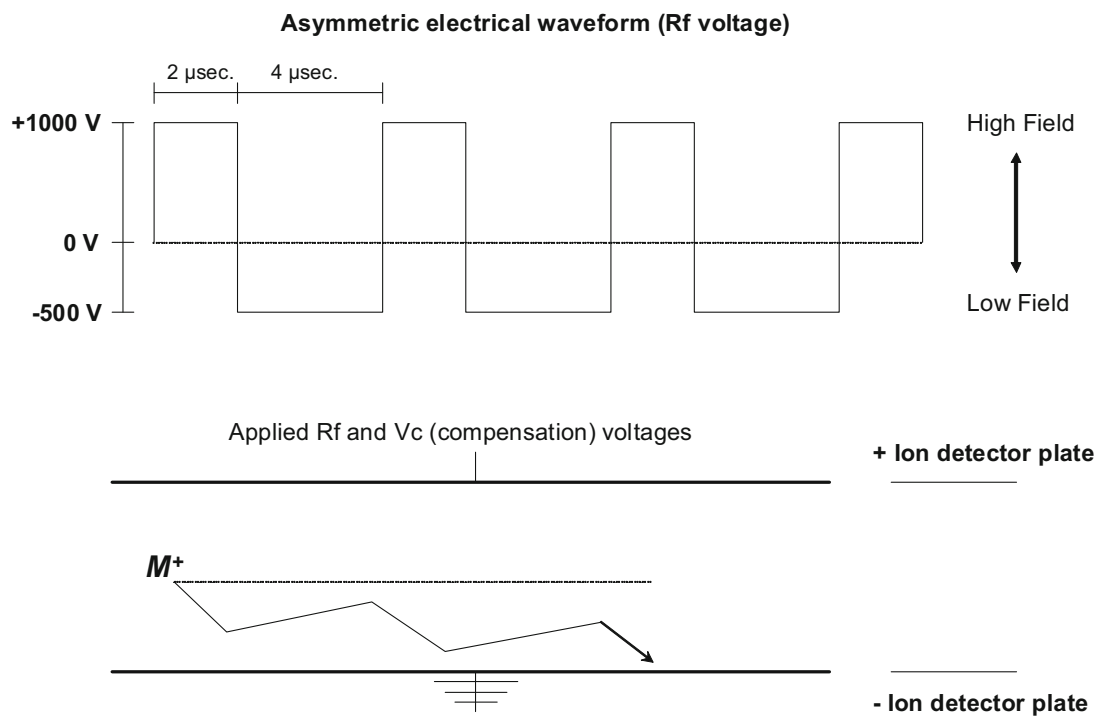

Figure 1. An ion trajectory between two parallel electrode plates as it experiences the asymmetric electrical waveform of $+1000 \mathrm{~V}$ for $2 \mu \mathrm{s}$, then $-500 \mathrm{~V}$ for $4 \mu \mathrm{s}$. 
of various salts to the sample solvent solutions for their effects on ionization and FAIMS selectivity [22]. They observed with an individual oligosaccharide sample (MW 512), the ESI formation of numerous oligosaccharide aggregate ions up to the limit of their $m / z$ scan range $(\mathrm{m} / \mathrm{z}$ 2000). While the most abundant ions formed for this sample were $\left[\mathrm{MNH}_{4}\right]^{+},[\mathrm{MNa}]^{+}$, $[\mathrm{MK}]^{+}$, in that order, examples of some aggregate ions of high abundance were $\left[\mathrm{M}_{2} \mathrm{Na}\right]^{+},\left[\mathrm{M}_{2} \mathrm{NH}_{4}\right]^{+}$, $\left[\mathrm{M}_{5}\left(\mathrm{NH}_{4}\right)_{2}\right]^{2+},\left[\mathrm{M}_{5}\left(\mathrm{NH}_{4}\right) \mathrm{Na}\right]^{2+},\left[\mathrm{M}_{3} \mathrm{Na}\right]^{+},\left[\mathrm{M}_{3} \mathrm{NH}_{4}\right]^{+}$, and $\left[\mathrm{M}_{10}\left(\mathrm{NH}_{4}\right)_{3}\right]^{3+}$. The formation of aggregate ions was problematic for them, as fragmentation would occur at the FAIMS-MS interface, resulting in poor FAIMS specificity. They state, "As a result, the $\left[\mathrm{MNH}_{4}\right]^{+}$would be detected not only at its original transmission $\mathrm{CV}$ of $2.9 \mathrm{~V}$ but also at $\mathrm{CVs}$ where ions associated with their fragmentation product $\left[\mathrm{MNH}_{4}\right]^{+}$ are transmitted through FAIMS. Low-energy conditions at the mass spectrometer interface help to differentiate ions formed in ESI from their dissociation products" [22]. In our study, we also observed oligosaccharide aggregate ion formation and dissociation at the MS interface. However, instead of relying on low-energy cone voltage settings of the mass spectrometer to reduce aggregate ion dissociation at the DMS-MS interface, we explored the use of various sample solvent systems to reduce aggregate ion formation in the ESI process. In this study we demonstrate the successful use of a tetrachloroethane/methanol solvent solution to reduce ESI oligosaccharide aggregate ion formation while efficiently forming a dominant $\mathrm{MH}^{+}$protonated molecule. By reducing aggregate ion formation, optimized MS cone voltage settings for maximum analyte ion abundance can be used without any detrimental effects on DMS selectivity and specificity. In addition to DMS and FAIMS, we would expect that our approach of reducing aggregate ion complexity would be beneficial to the analysis of oligosaccharides for other post ESI separation techniques such as ion mobility [23]. Based on the findings of Harvey et al., differences in $\mathrm{MH}^{+}$and $\mathrm{MNa}^{+}$fragmentation patterns of glycans, solvent selected control over $\mathrm{MH}^{+}$molecular ion formation may provide benefits for performing structural characterization analysis of glycans [18].

\section{Experimental}

\section{Instrumentation}

The nanoESI-DMS-MS system encompasses a modified Sionex Corporation microDMx differential mobility sensor (Sionex SDP-1), a Micromass ZQ detector (Beverly, MA), and a custom made nanospray source. The ESI source consists of a Valco microconnector union (Houston, TX) attached to a Newport micro movement plate with XYZ directional control. The ESI voltage is applied to the union where a liquid-liquid junction is created between peek tubing and a Proxeon nanobore steel emitter (part no. ES301, Denmark). The small size of the DMS sensor, 3 in. long, 1 in. high, and 1/4] in. wide, simplified interfacing to the mass spectrometer inlet. Samples were directly infused into the nanospray source via a Harvard syringe pump (Hamden, CT) at a flow of $350 \mathrm{~nL} / \mathrm{min}$. Sample analysis was performed in positive mode nanospray at a capillary voltage of $2 \mathrm{kV}$. A cone voltage of $40 \mathrm{~V}$ was applied to the inlet cone, and the inlet source temperature in the mass spectrometer was set to $50{ }^{\circ} \mathrm{C}$. Design details and a schematic of our nanoESI-DMS-MS system have been presented previously $^{\circ}[26]^{\circ}{ }^{\circ}$ The $^{\circ}$ vacuum $^{\circ}$ generated $^{\circ}$ by $^{\circ}$ the ${ }^{\circ}$ mass $^{\circ}$ spec- $^{-}$ trometer provided the gas flow (measured at approximately $1 \mathrm{~L} / \mathrm{min}$ ) through the sensor and into the mass spectrometer. A drift gas line opposite the sensor inlet had a constant flow of ultra high purity nitrogen at $\sim 0.52 \mathrm{~L} / \mathrm{min}$ (with or without the addition of modifier). A methanol drift gas modifier was introduced for selected tests at an approximate concentration of 8000 ppm of the total gas flow through the sensor. The design and operational details of the Sionex Corporation differential mobility sensors have been described previously ${ }^{\circ}\left[11,{ }^{\circ} 26,{ }^{\circ} 27\right] .{ }^{\circ}$ For $^{\circ}$ this $^{\circ}$ study, ${ }^{\circ}$ the $^{\circ}$ sensor ${ }^{\circ}$ was operated at ambient laboratory temperature.

\section{Materials and Reagents}

Oligosaccharide analytes maltopentaose and maltoheptaose were purchased from Sigma-Aldrich Corp., St. Louis, MO. Lacto-N-fucopentaose I (LNFP I) and lacto-N-fucopentaose II (LNFP II) oligosaccharides were purchased from GLYKO Inc., Novato, CA. HPLC grade water (Sigma), HPLC grade methanol (Sigma), and tetrachloroethane (Sigma) were used for sample preparation. $\mathrm{NaCl}$ used for sample solutions was purchased from J. T. Baker (Philipsburg, CT); $0.25 \mathrm{mg} / \mathrm{mL}$ oligosaccharide samples were prepared in solutions of either 50/50 water/methanol, 50/50 water/methanol with $2 \mathrm{mM} \mathrm{NaCl}$, methanol, methanol with $2 \mathrm{mM} \mathrm{NaCl}$, or $60 / 40$ methanol/tetrachloroethane.

\section{Procedures}

For each sample tested, a selected ion DMS spectrum was generated as follows. For a selected Rf voltage of either 1250 or $1500 \mathrm{~V}$, the compensation voltage was scanned from -25 to $+5 \mathrm{~V}$, in $0.12 \mathrm{~V}$ increments, over $4.2 \mathrm{~min}$. The MS signal was collected for the $\mathrm{m} / \mathrm{z}$ range of 200 to 2000 during the Vc scan. For any ion of interest (within $\mathrm{m} / \mathrm{z} 200$ to 2000), a DMS spectrum was generated from the selected ion MS signal. After the generation of selected ion DMS spectra, mass spectra were collected with the compensation voltage set to selected values. The Vc selected mass spectra are a $30 \mathrm{~s}$ average of the $0.36 \mathrm{~s}$ mass scans. Mass spectra were also collected for each sample condition with the DMS turned off, allowing all the ions to enter the mass spectrometer. 

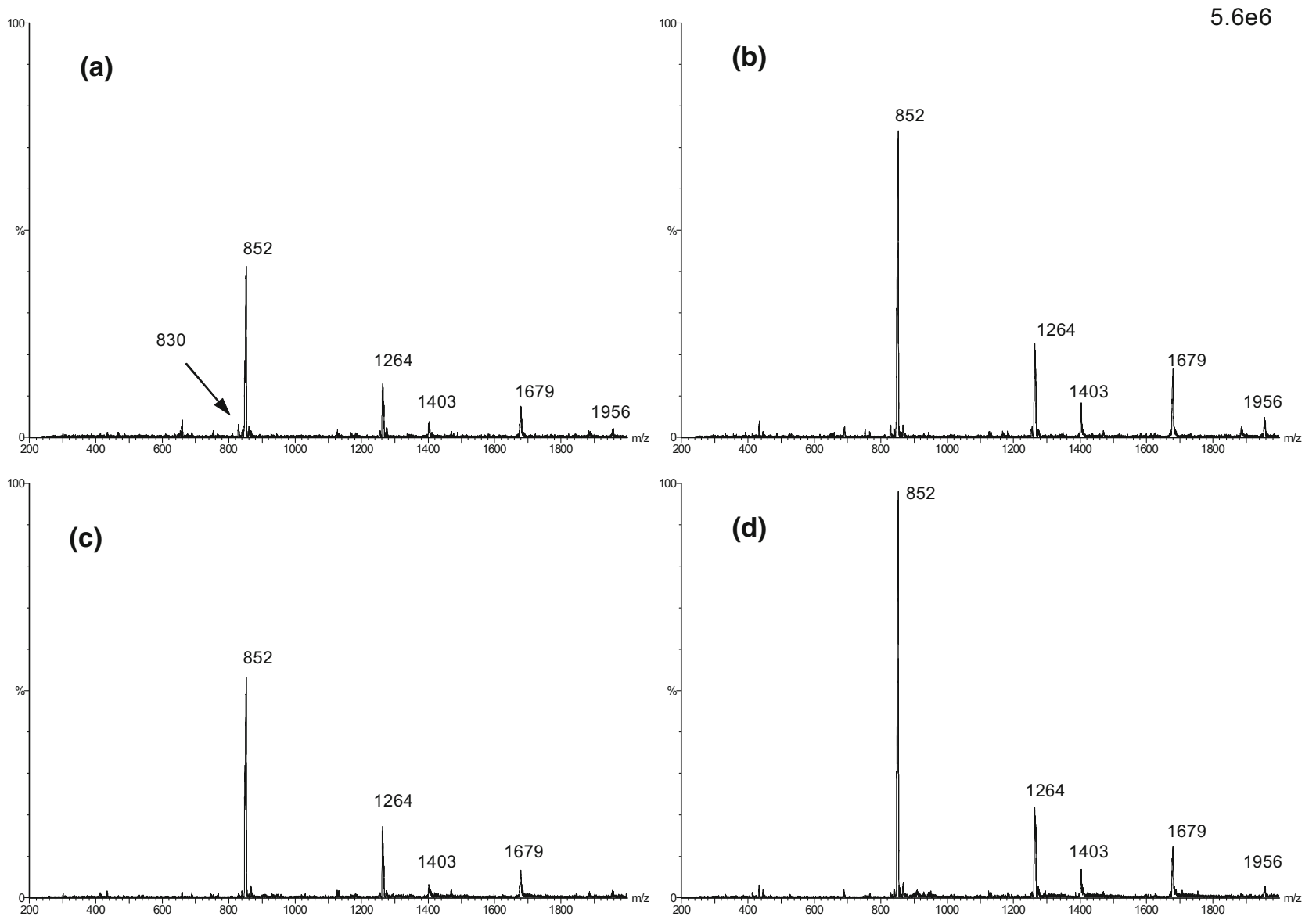

Figure 2. (a) Mass spectra (DMS turned off) of $0.25 \mathrm{mg} / \mathrm{mL}$ maltopentaose in 50/50 water / methanol, (b) same but with $8000 \mathrm{ppm}$ methanol drift gas modifier, (c) $0.25 \mathrm{mg} / \mathrm{mL}$ maltopentaose in 50/50 water/methanol $2 \mathrm{mM} \mathrm{NaCl}$, (d) same but with 8000 ppm methanol drift gas modifier. All spectra normalized to same ion signal scale.

\section{Results and Discussion}

\section{Oligosaccharide Ionization and DMS Separation}

Maltopentaose was selected as a test compound to evaluate the effects of various solvent compositions on the ESI formation of $\mathrm{MH}^{+}$and $\mathrm{MNa}^{+}$molecular ions, as well as aggregate ion formation and their effects on DMS separation. We have previously explored the use of polar drift gas modifiers to aid in the DMS separation of various compounds, and have found them particularly beneficial in the DMS analysis of large polar molecules ${ }^{\circ}$ such $^{\circ}$ as $^{\circ}$ peptides $/$ proteins $^{\circ}\left[26,{ }^{\circ} 27\right] .^{\circ} \operatorname{In}^{\circ}$ this study, we explore the use of 8000 ppm methanol as our drift gas modifier to improve the DMS separation capabilities $^{\circ}$ of $^{\circ}$ our $^{\circ}$ oligosaccharide $^{\circ}$ analytes. ${ }^{\circ}$ Figure $^{\circ} 2$ a and $c$ demonstrate the ions generated with use of a 50/50 methanol/water solvent composition, with and without $2 \mathrm{mM} \mathrm{NaCl}$, on the nanospray ionization of $0.25 \mathrm{mg} / \mathrm{mL}$ maltopentaose (DMS turned off, no ion selection). In both solvent systems the $m / z 852 \mathrm{MNa}^{+}$ ion is the most dominant peak in the mass spectrum. To minimize $\mathrm{Na}^{+}$ion contamination in our system, all non- $\mathrm{NaCl}$ containing solvent systems were analyzed before the $\mathrm{NaCl}$ containing solvents. As demonstrated in Figure 2a, with the use of fust $50 / 50$ methanol/water, residual $\mathrm{Na}^{+}$ion contamination dominates the formation of the $m / z 852 \mathrm{MNa}^{+}$ion (2.4e6 ion count) over the $\mathrm{m} / \mathrm{z} 830^{\circ} \mathrm{MH}^{+}{ }^{\circ} \operatorname{ion}^{\circ}\left(1.8 \mathrm{e}^{\circ}{ }^{\circ}\right.$ ion $^{\circ}$ count $) .{ }^{\circ}$ Figure ${ }^{\circ} 2 \mathrm{c}^{\circ}$ demonstrates that the addition of $2 \mathrm{mM} \mathrm{NaCl}$ to the solvent did not result in a significant increase to the $\mathrm{MNa}^{+}$ion (2.98e6 ion count), but did demonstrate a decrease of the $m / z 830$ ion signal to that of the spectral noise. The mass $^{\circ}$ spectra $^{\circ}$ in $^{\circ}$ Figure $^{\circ} 2 b^{\circ}$ and ${ }^{\circ} \mathrm{d}^{\circ}$ are $^{\circ}$ for ${ }^{\circ}$ the ${ }^{\circ}$ same samples ${ }^{\circ}$ as ${ }^{\circ}$ Figure $2 a^{\circ}$ and $^{\circ}{ }^{\circ}$, but ${ }^{\circ}$ with the $e^{\circ} e^{\circ}$ of the 8000 ppm methanol drift gas modifier, which resulted in a near 2-fold increase to the ion abundance of the $\mathrm{MNa}^{+}$ ion. ${ }^{\circ}$ For $^{\circ}$ all $^{\circ}$ spectra $^{\circ}$ in $^{\circ}$ Figure $^{\circ} 2^{\circ}$ it $^{\circ}$ is $^{\circ}$ evident $^{\circ}$ that

Table 1. Maltopentaose-sodium aggregate ion species and corresponding $\mathrm{m} / \mathrm{z}$ value

\begin{tabular}{ll}
\hline$m / z$ & \multicolumn{1}{c}{ Likely aggregate ion species } \\
\hline \hline 1264 & $(3 \mathrm{M}+2 \mathrm{Na})^{2+}$ or $(6 \mathrm{M}+4 \mathrm{Na})^{4+}$, etc. \\
1403 & $(5 \mathrm{M}+3 \mathrm{Na})^{3+}$ \\
1679 & $(2 \mathrm{M}+\mathrm{Na})^{+}$ \\
1956 & $(7 \mathrm{M}+3 \mathrm{Na})^{3+}$ \\
\hline
\end{tabular}



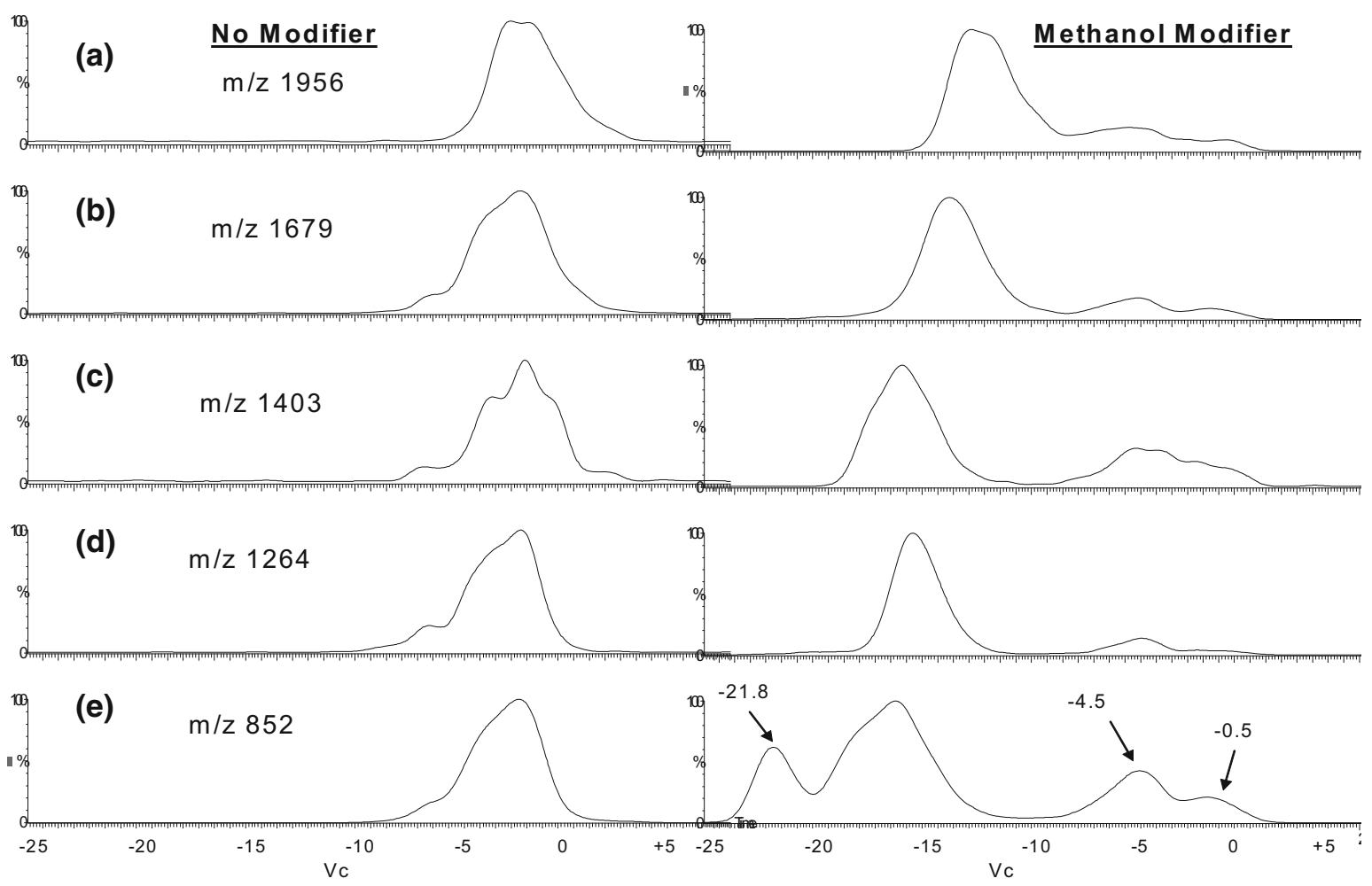

Figure 3. $0.25 \mathrm{mg} / \mathrm{mL}$ maltopentaose in $50 / 50$ methanol/water, selected ion DMS spectra for the $\mathrm{m} / \mathrm{z}$ 1956 ion (a), m/z 1679 ion (b), $m / z 1403$ ion (c), m/z 1264 ion (d), and $m / z 852$ ion (e). Rf set to $1500 \mathrm{~V}$ and $V_{c}$ scanned from -25 to $+5 \mathrm{~V}$, (left side without drift gas modifier, right side with $8000 \mathrm{ppm}$ methanol).

numerous ions in high abundance are present in addition to the $\mathrm{m} / \mathrm{z} 852 \mathrm{MNa}^{+}$ion. Many of these ions correspond to maltopentaose-sodium aggregate ion $\mathrm{m} / \mathrm{z}$ values; ${ }^{\circ}$ Table $1{ }^{\circ}$ lists $^{\circ}$ the ${ }^{\circ}$ aggregate ${ }^{\circ}$ ion ${ }^{\circ}$ species ${ }^{\circ}$ and ${ }^{\circ}$ their $\mathrm{m} / \mathrm{z}$ value. The $\mathrm{m} / \mathrm{z} 852$ ion signal may not represent solely the $\mathrm{MNa}^{+}$ion, but actually be the result of various $(\mathrm{nM}+\mathrm{nNa})^{n+}$ ion formations.

Due to the nature of differential mobility spectrometry, in that separation takes place post-ionization, the formation of numerous aggregate/cluster ions by ESI creates an unnecessarily complex ion population. We demonstrate an approach to overcome aggregate/cluster ion formation via ESI, reducing sample complexity, and improving specificity in the DMS analysis of oligosaccharides. First, we investigated the DMS separation of the maltopentaose $\mathrm{m} / \mathrm{z} 852 \mathrm{MNa}^{+}$ion, as well as many of the observed maltopentaose-sodium aggregate ions. ${ }^{\circ}$ Figure $^{\circ} 3 a-e^{\circ}$ demonstrate $^{\circ}$ the $^{\circ}$ selected $^{\circ}$ ion $^{\circ}$ DMS spectra for the $m / z 1956$ ion (a), $m / z 1679$ ion (b), $m / z$ 1403 ion (c), $m / z 1264$ ion (d), and $m / z 852$ ion (e), all generated from the $0.25 \mathrm{mg} / \mathrm{mL}$ maltopentaose sample in 50/50 methanol/water, with and without the use of the $8000 \mathrm{ppm}$ methanol drift gas modifier. The selected ion ${ }^{\circ} \mathrm{DMS}^{\circ}$ spectra ${ }^{\circ}{ }^{\circ} \mathrm{Figure}^{\circ}{ }^{\circ}$ were ${ }^{\circ}$ collected ${ }^{\circ} y^{\circ}$ scanning the compensation voltage $(\mathrm{Vc})$ from -25 to $+5 \mathrm{~V}$ at an Rf of $1500 \mathrm{~V}$. All of the DMS spectra on the left side of Figure $3^{\circ}$ are $^{\circ}$ generated ${ }^{\circ}$ without $^{\circ}$ the $e^{\circ}$ use ${ }^{\circ}$ of ${ }^{\circ}$ the ${ }^{\circ}$ methanol drift gas modifier, whereas all of the spectra on the right are with the use of the methanol drift gas modifier. As can be seen, the use of the drift gas modifier provided a shift in signal to larger negative $\mathrm{V}_{\mathrm{c}}$ values for all selected ions of interest and, in addition, resulted in the generation of multiple DMS spectral peaks for each ion over a large $V_{c}$ range. We have previously demonstrated the use of polar drift gas modifiers to reduce the clustering of peptides and improve DMS separation analysis ${ }^{\circ}[26]^{\circ}{ }^{\circ} \mathrm{We}{ }^{\circ}$ hypothesize, ${ }^{\circ}$ that ${ }^{\circ}$ the ${ }^{\circ}$ methanol ${ }^{\circ} \mathrm{drift}$ gas modifier interacts with the maltopentaose-sodium aggregate ions in the gas-phase, and competes with the $\mathrm{H}$-bonding and Van der Waals forces driving the clustering, and in turn facilitates cluster dissociation and reduced ion cross sections, increasing the DMS separation capabilities. As discussed previously, and observed by $^{\circ}$ Gabryelski $^{\circ}$ et $^{\circ}$ al. $^{\circ}[22]^{\circ}$, the $^{\circ}$ multiple ${ }^{\circ} \mathrm{DMS}^{\circ}$ spectra peaks observed for each ion are generated by either the Vc position of the selected ion itself or the ion signal of a fragment ion dissociated from a larger cluster ion transmitted ${ }^{\circ}$ at $^{\circ} \mathrm{a}^{\circ}$ lower $^{\circ} \mathrm{VC}^{\circ}$ position. ${ }^{\circ}$ Figure $^{\circ} 4 \mathrm{a}^{\circ}$ and ${ }^{\circ} \mathrm{b}$ demonstrate mass spectra at selected compensation voltages $^{\circ}$ for $^{\circ}$ the $e^{\circ} \mathrm{DMS}^{\circ}$ spectra $^{\circ}$ shown ${ }^{\circ}$ in ${ }^{\circ}$ Figure $^{\circ} 3 .^{\circ}$ Figure $^{\circ} 4 \mathrm{a}$ shows the mass spectra collected with the $V_{c}$ set to $-21.8 \mathrm{~V}$, corresponding to the apex of the left most DMS $^{\circ}$ spectrum $^{\circ}$ peak $^{\circ}$ in $^{\circ}$ Figure $^{\circ} 3 \mathrm{e}^{\circ}$ (with ${ }^{\circ}$ methanol). Figure $^{\circ} 4 \mathrm{~b}^{\circ}$ shows $^{\circ}$ the ${ }^{\circ}$ mass $^{\circ}$ spectra $^{\circ}$ collected $^{\circ}$ at $^{\circ} \mathrm{a}^{\circ} \mathrm{Vc}_{\mathrm{c}}$ 

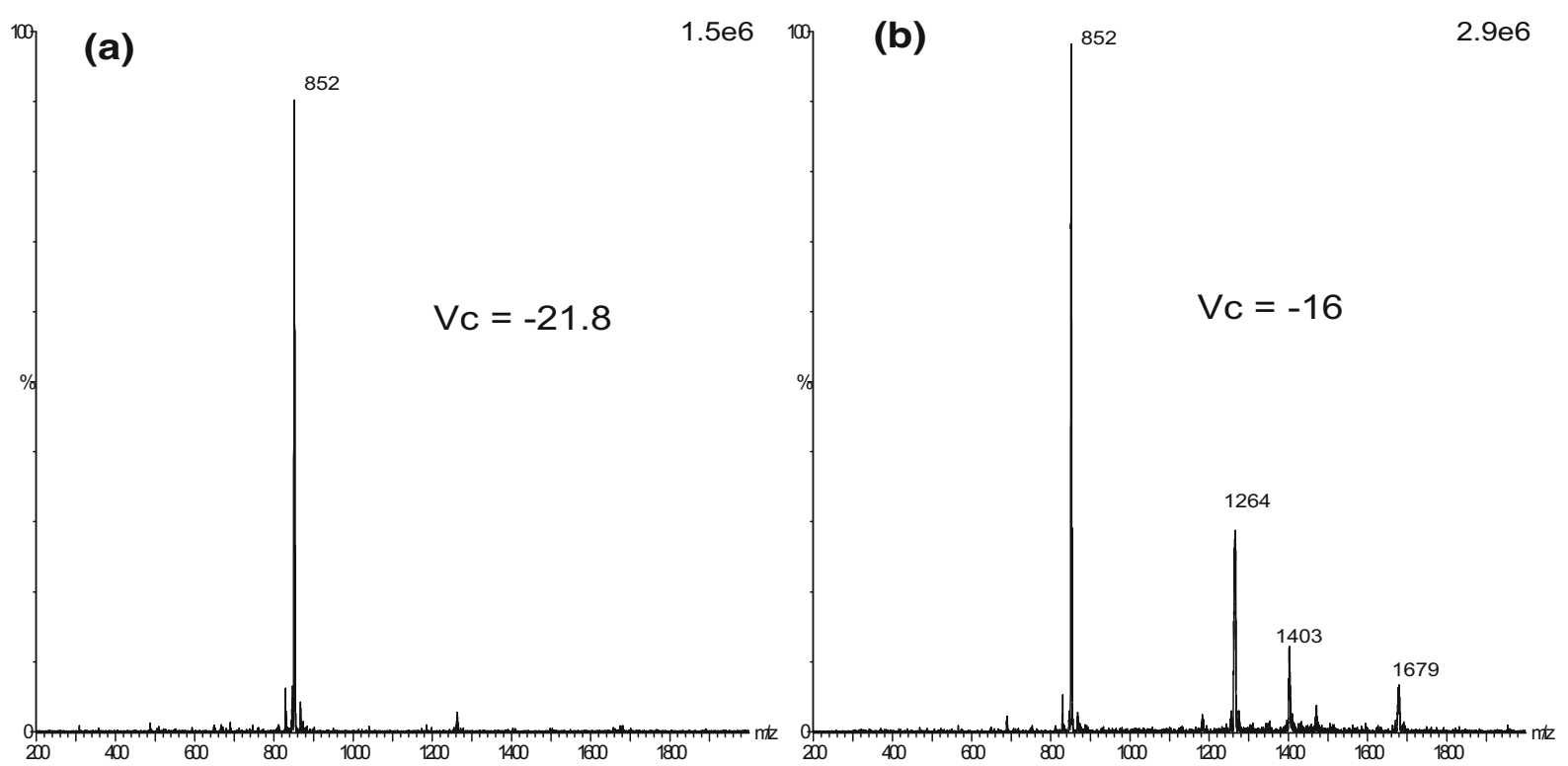

Figure 4. Mass spectra for $0.25 \mathrm{mg} / \mathrm{mL}$ maltopentaose in 50/50 methanol/water at selected compensation $^{\circ}$ voltages ${ }^{\circ}$ from ${ }^{\circ}$ analysis ${ }^{\circ}$ in ${ }^{\circ}$ Figure $^{\circ} 3^{\circ}$ ( with $^{\circ}$ methanol $^{\circ} \mathrm{drift}^{\circ}$ gas $^{\circ}$ modifier $),{ }^{\circ}-21.8^{\circ} \mathrm{V}^{\circ}(\mathbf{a}),{ }^{\circ}$ and $-16 \mathrm{~V}$ (b) with Rf set to $1500 \mathrm{~V}$.

setting ${ }^{\circ} \mathrm{of}^{\circ}-16^{\circ}$ in $^{\circ}$ each $^{\circ}$ of $^{\circ}$ Figure $^{\circ} 3 \mathrm{~b}-\mathrm{e}^{\circ}$ (with ${ }^{\circ}$ methanol). The $^{\circ}$ comparison $^{\circ}$ between ${ }^{\circ}$ the $^{\circ}$ mass $^{\circ}$ spectra $^{\circ}$ in $^{\circ}$ Figure $^{\circ} 4$ reflects what is assumed to be the DMS separation of the $m / z 852 \mathrm{MNa}^{+}$ion $(\mathrm{Vc}=-21.8 \mathrm{~V}$ ) from larger aggregate ions $\left(\mathrm{V}_{\mathrm{c}}=-16\right)$. Of significance, is the comparison between the $\mathrm{m} / \mathrm{z} 852$ ion abundance in Figure ${ }^{\circ} 4 a^{\circ}$ and ${ }^{\circ} b,{ }^{\circ}$ which ${ }^{\circ}$ imply, ${ }^{\circ}$ along ${ }^{\circ}$ with ${ }^{\circ}$ the ${ }^{\circ}$ separate peaks ${ }^{\circ}$ observed ${ }^{\circ}$ in $^{\circ}$ Figure $^{\circ} 3 \mathrm{e}^{\circ}$ (methanol), , that $^{\circ} \mathrm{a}^{\circ}$ significant portion of the total $\mathrm{m} / \mathrm{z} 852$ ion abundance observed in ${ }^{\circ}$ Figure $2 b^{\circ}$ is ${ }^{\circ}$ the ${ }^{\circ}$ result ${ }^{\circ}$ of ${ }^{\circ}\left(\mathrm{nM}^{\circ}+{ }^{\circ} \mathrm{nNa}\right)^{n+}$ aggregate ${ }^{\circ}$ ions with a $m / z$ of 852 , and/or non $(\mathrm{nM}+\mathrm{nNa})^{n+}$ aggregate ion dissociation at the MS inlet resulting in the formation of a $m / z 852$ ion.

Two DMS spectral peaks are observed for all of the selected ${ }^{\circ} \mathrm{m} / \mathrm{z}$ values ${ }^{\circ}{ }^{\circ}{ }^{\circ}$ Figure $^{\circ} 3 a-e^{\circ}$ (with ${ }^{\circ}$ methanol ${ }^{\circ} \mathrm{drift}$ gas modifier) at approximate $V_{c}$ values of -4.5 and -0.5 . These two spectral peaks are likely the result of maltopentaose-sodium aggregate ions with larger cross sections than the $m / z 1956(7 \mathrm{M}+3 \mathrm{Na})^{3+}$ ion. It is also possible that multiple spectral peaks for a selected ion signal could be the result of the DMS separation of different maltopentaose-sodium aggregate ions with identical $m / z$ values but different cross sections, such as $(2 \mathrm{M}+\mathrm{Na})^{+}$and $(4 \mathrm{M}+2 \mathrm{Na})^{2+}$, both with $\mathrm{m} / \mathrm{z} 1679$. The presence of multiple DMS spectral peaks for a selected ion signal increases the complexity for accurate oligosaccharide analysis by ESI-DMS-MS. Gabryelski et al. overcame this problem by decreasing the MS inlet voltage settings, in turn reducing dissociation of aggregate ions as they pass through the MS inlet, and eliminating the generation of multiple compensation voltage spectral peaks for a selected ion. Our concern with using this approach is that the appropriate MS inlet voltage settings are likely to be ion specific, requir- ing a screening approach to determine when aggregate ion dissociation is eliminated. This becomes problematic when analyzing unknown oligosaccharides, where specificity of the ion in question (monomer or aggregate) becomes blurred. In addition, the reduction of the MS inlet voltages typically results in decreased analyte ion signal, which is significant for compounds such as oligosaccharides that often exhibit poor ionization efficiency in positive ESI. To circumvent this problem, we explored the use of various sample solvent systems to reduce the formation of oligosaccharide aggregate ions and improve the ion concentration of a single molecular ion.

\section{Oligosaccharide Aggregate Ion Reduction}

We hypothesized that the water present in our 50/50 methanol/water sample solvent may be a driving force for the formation of aggregate ions. Thus, as a first step, we prepared $0.25 \mathrm{mg} / \mathrm{mL}$ maltopentaose samples in $100 \%$ methanol with and without $2 \mathrm{mM} \mathrm{NaCl}$. However, simple removal of water from the sample solution did not result in the reduction of aggregate ion formation. All of the data for the $100 \%$ methanol conditions, both ion formation and DMS separation of the various ions, appeared consistent with what was observed for the 50/50 methanol/water sample solvent conditions (data not shown).

A second approach for reducing the formation of aggregate ions by modifying the sample solvent was investigated. Of significance is that all of the abundant $^{\circ}$ aggregate $^{\circ}$ ions $^{\circ}$ observed $^{\circ}$ in $^{\circ}$ Figure $^{\circ} 2^{\circ}$ are $^{\circ}$ the result of maltopentaose- $\mathrm{Na}^{+}$complexation and not maltopentaose- $\mathrm{H}^{+}$aggregates (dimer, trimer, etc.). 


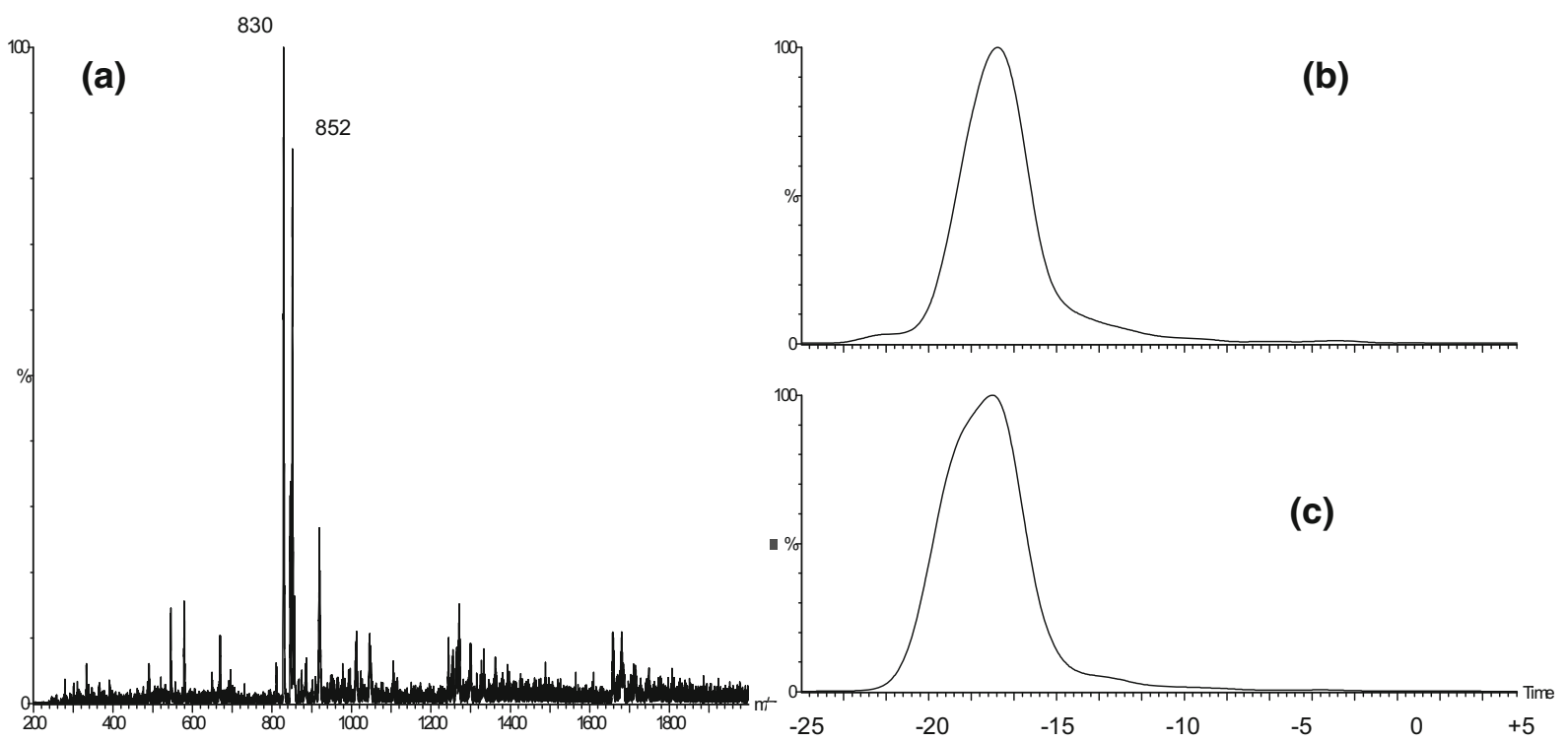

Figure 5. (a) Mass spectra of $0.25 \mathrm{mg} / \mathrm{mL}$ maltopentaose in $60 / 40$ methanol/tetrachloroethane, with $8000 \mathrm{ppm}$ methanol dopant (DMS turned off), (b) $\mathrm{m} / \mathrm{z} 852$ selected ion DMS spectra at $\mathrm{Rf}=1500$, and (c) $\mathrm{m} / \mathrm{z} 830$ selected ion DMS spectra at $\mathrm{Rf}=1500$.

The use of the solvent tetrachloroethane as part of our sample solution was investigated with the hypothesis that it would act as a chelating agent for residual $\mathrm{Na}^{+}$ and other interfering cations, reducing aggregate ion formation and enhancing the ESI formation of the molecular $\mathrm{MH}^{+}$ion. However, the use of $100 \%$ tetrachloroethane as the sample solvent was not successful because the solvent is not hydrophilic enough to solubilize maltopentaose. On the other hand, since methanol and tetrachloroethane are miscible with one another a solution of $60 / 40$ methanol/tetrachloroethane was explored next and proved to provided sufficient hydrophilicity ${ }^{\circ}$ for $^{\circ}$ this ${ }^{\circ}$ purpose. ${ }^{\circ}$ Figure ${ }^{\circ} 5 a-\varepsilon^{\circ}$ demonstrate $^{\circ}$ the ${ }^{\circ}$ mass spectra (DMS turned off) for the $0.25 \mathrm{mg} / \mathrm{mL}$ maltopentaose sample in 60/40 methanol/tetrachloroethane with the $8000 \mathrm{ppm}$ methanol drift gas modifier (a), the $\mathrm{m} / \mathrm{z}$ 852 selected ion DMS spectra at $\mathrm{Rf}=1500(\mathrm{~b})$, and the $\mathrm{m} / \mathrm{z} 830$ selected ion DMS spectra at $\mathrm{Rf}=1500$ (c). The use of the methanol/tetrachloroethane sample solvent resulted in the ESI formation of a dominant $\mathrm{m} / \mathrm{z} 830$ $\mathrm{MH}^{+}{ }^{\circ}$ molecularion. ${ }^{\circ}{ }^{\circ}$ ompared ${ }^{\circ}{ }^{\circ}$ ith $^{\circ}$ Figure $2 \mathrm{c},{ }^{\circ}$ the ${ }^{\circ} \mathrm{m} / \mathrm{z}$ $830^{\circ}$ ion $^{\circ}$ abundance ${ }^{\circ}$ in $^{\circ}$ Figure $^{\circ} 5 \mathrm{a}^{\circ}$ is ${ }^{\circ} \sim 6.5$-fold ${ }^{\circ}$ greater, whereas the $m / z 852 \mathrm{MNa}^{+}$ion abundance decreased around 4.8 fold. In addition, only a single $\mathrm{m} / \mathrm{z} 852$ peak is ${ }^{\circ}$ present ${ }^{\circ}$ in $^{\circ}$ Figure $^{\circ} 5 \mathrm{~b}^{\circ}$ compared $^{\circ}{ }^{\circ} 0^{\circ}$ the ${ }^{\circ}$ multiple ${ }^{\circ}$ peaks in $^{\circ}$ Figure $^{\circ} 3 e^{\circ}$, demonstrating $^{\circ} a^{\circ}$ reduction $^{\circ}$ in ${ }^{\circ}$ the ${ }^{\circ}$ ESI formation of numerous maltopentaose-sodium aggregate ions. With the successful reduction of aggregate ion formation through the use of the 60/40 methanol/ tetrachloroethane solution, the use of this sample solvent to aid in the DMS separation of two different oligosaccharides was investigated.

The use of the $60 / 40$ methanol/tetrachloroethane sample solvent provided the desired results with regards to molecular $\mathrm{MH}^{+}$ion formation and reduc- tion in aggregate ion formation. Apparently, the formation of salt bridges is a major component to the formation of oligosaccharide aggregate ions. While the use of tetrachloroethane resulted in lower ion abundance for analyte detection, these improvements enabled the generation of a single DMS spectrum peak, ${ }^{\circ}$ as ${ }^{\circ}$ presented $^{\circ}$ in $^{\circ}$ Figure $^{\circ} 5,{ }^{\circ}$ compared $^{\circ}$ with $^{\circ}$ the multiple peaks related to aggregate ion dissociation, as $^{\circ}$ presented ${ }^{\circ}$ in ${ }^{\circ}$ Figure $^{\circ} 3 .^{\circ}$ The $^{\circ}$ generation ${ }^{\circ}$ of ${ }^{\circ} a^{\circ}$ single DMS spectral peak, for a given analyte, improves the capability to distinguish the optimum DMS conditions for the separation of two or more oligosaccharides. An oligosaccharide mixture of $0.25 \mathrm{mg} / \mathrm{mL}$ each of maltopentaose and maltoheptaose (MW 1153) was prepared in the 60/40 methanol/tetrachloroethane solvent and was used to investigate DMS separation ${ }^{\circ}$ of $^{\circ}$ two $^{\circ}$ oligosaccharides. $^{\circ}{ }^{\text {Figure }}{ }^{\circ} 6 a-{ }^{\circ}{ }^{\circ} \operatorname{show}^{\circ}(a)$ the mass spectra (DMS turned off) for the maltopentaose/ maltoheptaose sample with the $8000 \mathrm{ppm}$ methanol drift gas modifier, (b) the $\mathrm{m} / \mathrm{z} 1154$ selected ion DMS spectra at $\mathrm{Rf}=1250$, (c) the $\mathrm{m} / \mathrm{z} 830$ selected ion DMS spectra at $\mathrm{Rf}=1250$, (d) the mass spectra collected with the $\mathrm{Vc}_{\mathrm{c}}$ set to $-12.5(\mathrm{Rf}=1250)$, and (e) the mass spectra collected with the Vc set to $-8.7 \mathrm{~V}$ $\left(\mathrm{Rf}^{\circ}={ }^{\circ} 1250\right) .{ }^{\circ}{ }^{\circ} s^{\circ}$ demonstrated ${ }^{\circ}$ in $^{\circ}{ }^{\circ}$ Figure $^{\circ} 6 \mathrm{a},{ }^{\circ}$ the ${ }^{\circ}$ two most abundant ions present are the $\mathrm{m} / \mathrm{z} 1154$ maltoheptaose $\mathrm{MH}^{+}$ion and the $\mathrm{m} / \mathrm{z} 830$ maltopentaose $\mathrm{MH}^{+}$ion. The use of the tetrachloroethane/methanol solution resulted in a single DMS spectral peak for each oligosaccharide $\mathrm{MH}^{+}$ion signal. Unlike the $\mathrm{DMS}^{\circ}$ spectra ${ }^{\circ}$ shown $^{\circ}$ in $^{\circ}$ Figure 3 e, , unambiguous ${ }^{\circ}$ identification for each analyte's spectral peak position can be $^{\circ}$ made $^{\circ}$ in $^{\circ}$ Figure $^{\circ} 6 \mathrm{~b}^{\circ}$ and $^{\circ} \mathrm{c}^{\circ} .^{\circ}{ }^{\circ}$ clear $^{\circ}$ separation ${ }^{\circ}$ of peak apex Vcs exists between maltopentaose $(-12.5$ $\mathrm{V})$ and maltoheptaose $(-8.7 \mathrm{~V})$. The mass spectra 

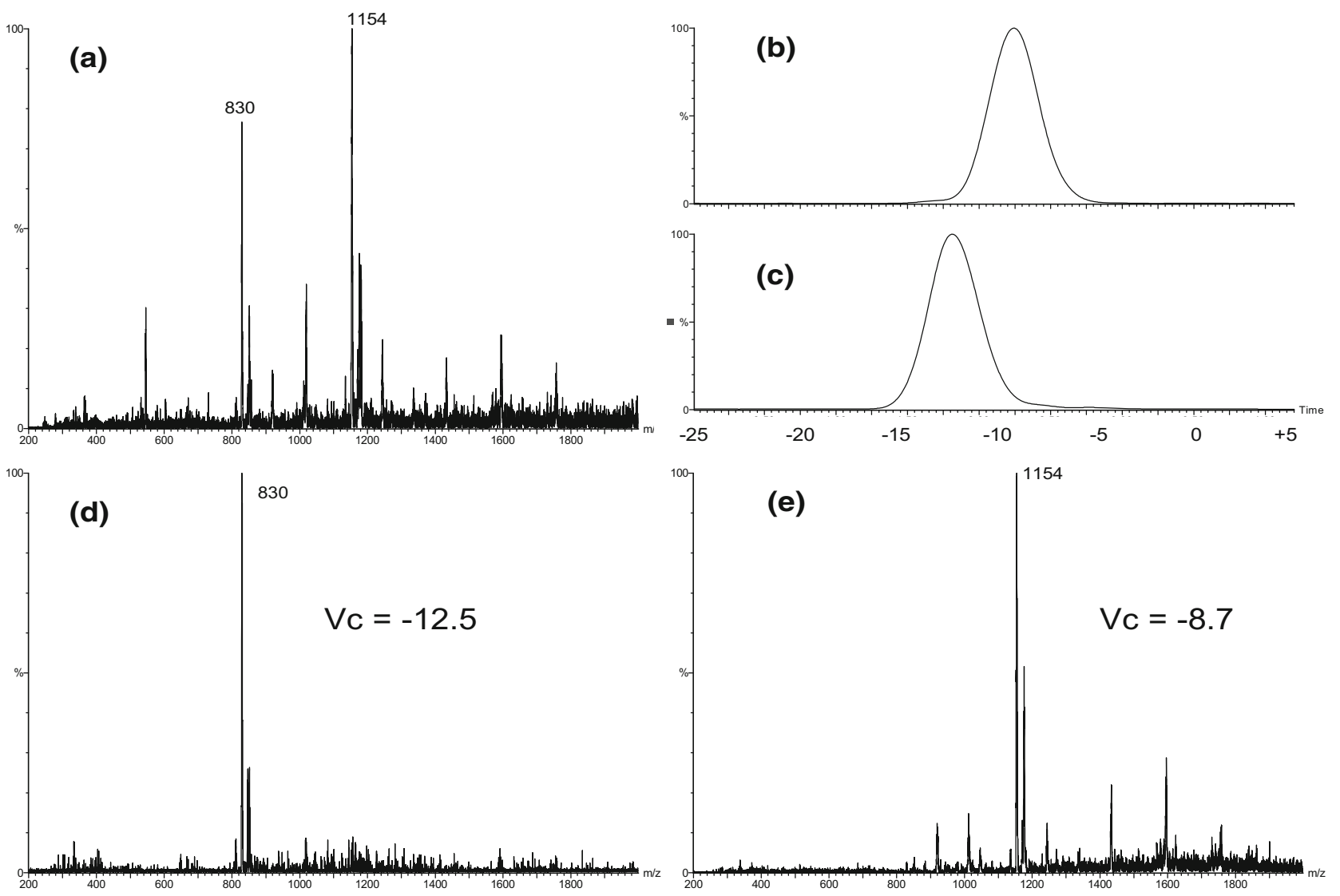

Figure 6. (a) Mass spectra (DMS turned off) of $0.25 \mathrm{mg} / \mathrm{mL}$ each maltopentaose and maltoheptaose in 60/40 methanol/tetrachlorethane with the $8000 \mathrm{ppm}$ methanol drift gas modifier, (b) the $\mathrm{m} / \mathrm{z} 1154$ selected ion DMS spectra at $\mathrm{Rf}=1250$, (c) the $m / z 830$ selected ion DMS spectra at $\mathrm{Rf}=1250$, (d) the mass spectra collected with the Vc set to $-12.5(\mathrm{Rf}=1250)$, and $(\mathbf{e})$ the mass spectra collected with the Vc set to $-8.7 \mathrm{~V}(\mathrm{Rf}=1250)$.

collected with the $V_{c}$ set to the respective peak apexes, ${ }^{\circ}$ shown $^{\circ}$ in $^{\circ}$ Figure $^{\circ} 6 \mathrm{~d}^{\circ}$ and $^{\circ} \mathrm{e},{ }^{\circ}$ demonstrate ${ }^{\circ}$ the DMS separation of the maltopentaose and maltoheptaose $\mathrm{MH}^{+}$ions.

\section{Oligosaccharide Isomer Separation}

To further investigate the potential for DMS separation of oligosaccharides, the isomers LNFP I and LNFP II (MW 854) were prepared separately in 60/40 methanol/ tetrachlorethane and analyzed with 8000 ppm methanol drift gas modifier. No difference in DMS spectral peak position was observed for the two LNFP $\mathrm{MH}^{+}$ions. Their selected ion DMS spectral peak apex Vcs at $\mathrm{Rf}=$ 1250 and $\mathrm{Rf}=1500$ were the same (data not shown). Figure \%a- $\varepsilon^{\circ}$ demonstrate ${ }^{\%}$ the ${ }^{\circ}$ ass $^{\circ}$ spectra ${ }^{\circ}$ (DMS turned off) for the $0.25 \mathrm{mg} / \mathrm{mL}$ LNFP I sample with the 8000 ppm methanol drift gas modifier (a), the LNFP I sample $\mathrm{m} / \mathrm{z} 855$ selected ion DMS spectra at $\mathrm{Rf}=1250$ (b), and the collected mass spectra for $\mathrm{V}_{\mathrm{c}}=-8.7 \mathrm{~V}$ (c). Consistent with the data obtained with maltopentaose and maltoheptaose, the use of the 60/40 methanol/ tetrachloroethane solution for LNFP I and II provided the dominant ESI formation of the oligosaccharide
$\mathrm{MH}^{+}$ion and a single DMS spectral peak. The selected ion $^{\circ} \mathrm{DMS}^{\circ}$ spectrum $^{\circ}$ in ${ }^{\circ}$ Figure $^{\circ} \mathrm{7b}^{\circ}$ has $^{\circ} \mathrm{a}^{\circ}$ signal $^{\circ}$ to ${ }^{\circ}$ noise ratio of $\sim 688$ for the observed peak. In contrast, the mass spectral signal-to-noise ratio for the $\mathrm{m} / \mathrm{z} 855$ ion in Figure $^{\circ} 7 \mathrm{a}^{\circ}$ is ${ }^{\circ} \sim 28 .^{\circ}{ }^{\circ}$ This $^{\circ}$ improvement $^{\circ}$ in ${ }^{\circ}$ signal/noise demonstrates the power of DMS to separate background ion noise and improve sensitivity for the ion of interest. Previously we have demonstrated the use of a rapid Vc scanning platform (10 s or less) for quantitative $^{\circ}$ analysis $^{\circ}$ of $^{\circ}$ peptides $^{\circ}[26] . .^{\circ}$ The $^{\circ}$ improvements ${ }^{\circ}$ to signal/noise and the rapid separation capabilities provided by this approach demonstrate promise for utilizing this rapid Vc scanning analysis platform for ultrahigh throughput quantitative analysis.

\section{Conclusions}

In this study, we demonstrate the use of a novel nanoESI-DMS-MS system for the analysis of oligosaccharides. Of significant interest is the demonstration of the importance of sample solvent selection in glycan cluster ion formation and its effects on glycan ionization and DMS separation. A tetrachloroethane/methanol solvent solution is introduced to reduce ESI oligosac- 


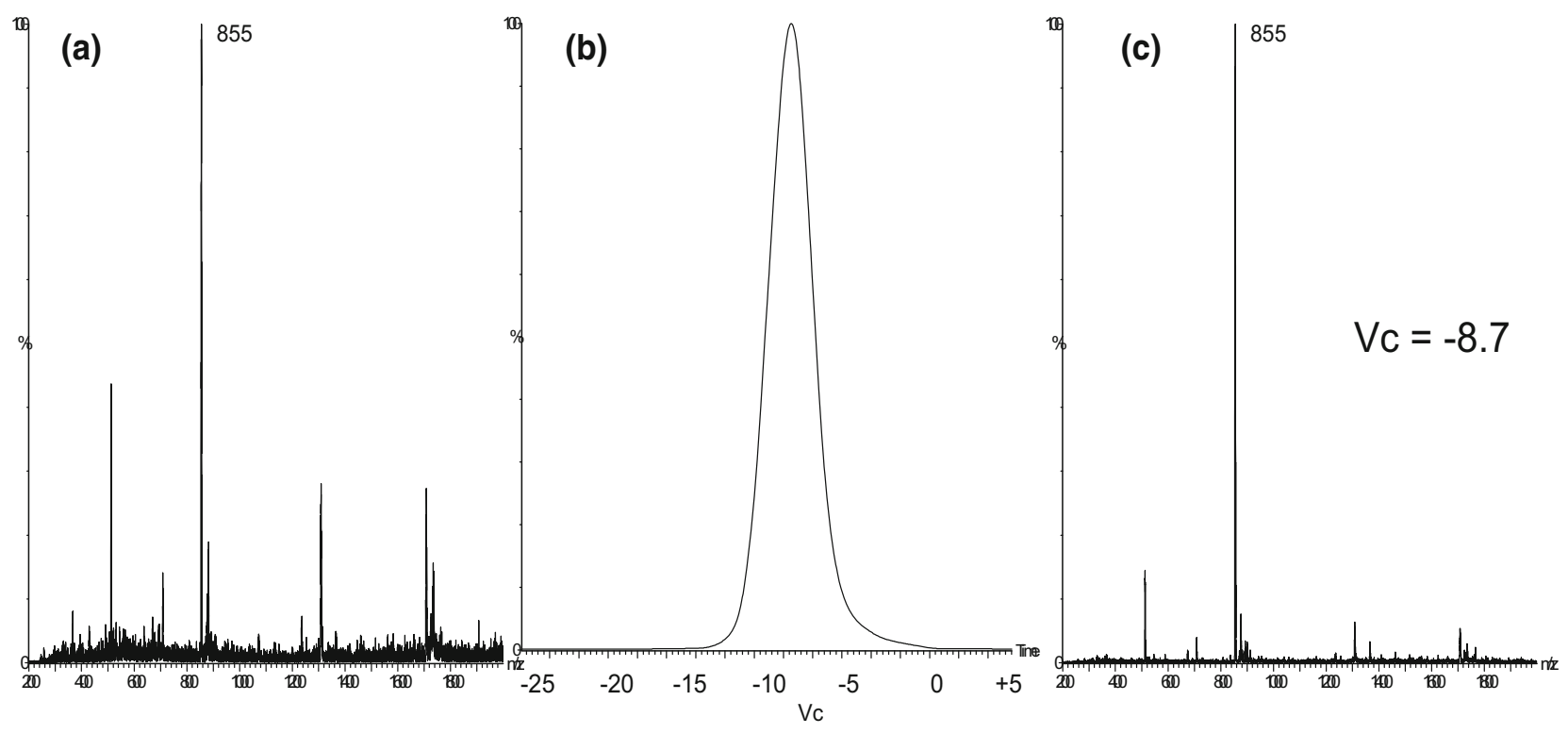

Figure 7. the mass spectra (DMS turned off) for the $0.25 \mathrm{mg} / \mathrm{mL}$ LNFP I sample in $60 / 40$ methanol/tetrachloroethane with the $8000 \mathrm{ppm}$ methanol drift gas modifier (a), the LNFP I sample $\mathrm{m} / \mathrm{z} 855$ selected ion DMS spectra at $\mathrm{Rf}=1250(\mathbf{b})$, and the collected mass spectra for $\mathrm{Vc}=-8.7 \mathrm{~V}(\mathbf{c})$.

charide aggregate ion formation while efficiently forming a dominant $\mathrm{MH}^{+}$molecular ion. By reducing aggregate ion formation, optimized MS cone voltage settings for maximum analyte ion abundance can be used without any negative affects on DMS separation analysis. In addition to DMS and FAIMS, we would expect this approach in reducing aggregate ion complexity to be beneficial to the analysis of oligosaccharides for other post ESI separation techniques such as ion-mobility ${ }^{\circ}[23]{ }^{\circ}{ }^{\circ}{ }^{\circ}{ }^{\circ}$ addition ${ }^{\circ}$ to ${ }^{\circ}$ the ${ }^{\circ}$ capability ${ }^{\circ}$ for ${ }^{\circ}$ stand alone nanoESI-DMS-MS oligosaccharide analysis, the results presented in this study reflect the potential for DMS based improvements to the specificity and signal-to-noise ratio for various types of MS based analyses, such as LC-MS and CE-MS. Based on the findings of Harvey et al. on differences in $\mathrm{MH}^{+}$and $\mathrm{MNa}^{+}$fragmentation patterns of glycans, solvent selected control over $\mathrm{MH}^{+}$molecular ion formation may provide benefits for performing structural ${ }^{\circ}$ characterization $^{\circ}$ analysis $^{\circ}$ of $^{\circ}$ glycans $^{\circ}[18]$.

\section{Acknowledgments}

This work was supported in part by a grant (PV) from the National Institutes of Health (1RO1CA69390). This is contribution number 899 from the Barnett Institute.

\section{References}

1. Buryakov, I. A.; Krylov, E. V.; Nazarov, E. G.; Rasulev, U. K. A New Method of Separation of Multi-Atomic Ions by Mobility at Atmospheric Pressure Using a High-Frequency Amplitude-Asymmetric Strong Electric Field. Int. J. Mass Spectrom. Ion Processes 1993, 128, 143-148.

2. Purves, R. W.; Guevremont, R.; Day, S.; Pipich, C. W.; Matyjaszcyk, M. S. Mass Spectrometric Characterization of a High-Field Asymmetric Waveform Ion Mobility Spectrometer. Rev. Sci. Instrum. 1998, 69, 4094-4105.

3. Carnahan, B.; Day, S.; Kouznetsov, V.; Tarassov, A. Proceedings of the Fourth International Workshop on Ion Mobility; August 1995, Cambridge, MA.
4. Elbein, A. D. The Role of $N$-Linked Oligosaccharides in Glycoprotein Function. Trends Biotechnol. 1991, 9, 346-352.

5. Broxterman, H. J.; Schurhuis, G. J.; Lankelma, J. Highly Sensitive and Specific Detection of P-Glycoprotein Function for Hematological and Solid Tumor Cells Using a Novel Nucleic Acid Stain. Br. J. Cancer 1997, 76, 1029-1034.

6. Bossart, K. N.; Wang, L. F.; Eaton, B. T. Functional Expression and Membrane Fusion Tropism of the Envelope Glycoproteins of Hendra Virus. Virology 2001, 290, 121-135.

7. Helenius, A.; Aebi, M. Intracellular Function of N-Linked Glycans. Science 2001, 291, 2364-2369.

8. Sheeley, D. M.; Reinhold, V. N. Structural Characterization of Carbohydrate Dequence, Linkage, and Branching in a Quadrupose Ion Trap Mass Spectrometer: Neutral Oligosaccharides and N-Linked Glycans. Anal. Chem. 1998, 70, 3053-3059.

9. Charlwood, J.; Birrell, H.; Tolson, D.; Camilleri, P. Polymorphism and Identification of Metallothionein Isoforms by Reversed-Phase HPLC with On-Line Ion-Spray Mass Spectrometric Detection. Anal. Chem. 1998, 70, 2530-2535.

10. Huang, Y.; Mechref, Y.; Novotny, M. V. Micrscale Nonreductive Release of O-Lilnked Glycans for Subsequent Analysis through MALDI Mass Spectrometry and Capillary Electrophoresis. Anal. Chem. 2001, 73, 6063-6069.

11. Miller, R. A.; Eiceman, G. A.; Nazarov, E. G.; King, A. T. A Novel Micromachined High-Field Asymmetric Waveform-Ion Mobility Spectrometer. Sens. Actuators B 2000, 67, 300-306.

12. Miller, R. A.; Nazarov, E. G.; Eiceman, G. A.; King, A. T. A MEMS Radio-Frequency Ion Mobility Spectrometer for Chemical Vapor Detection. Sens. Actuators A 2001, 91, 307-318.

13. Harvey, D. J. Ionization and Collision-Induced Fragmentation of NLinked and Related Carbohydrates Using Divalent Cations. J. Am. Soc. Mass Spectrom. 2001, 12, 926-937.

14. Wuhrer, M.; Koeleman, C. A. M.; Deelder, A. M.; Hokke, C. H Normal-Phase Nanoscale Liquid Chromatography-Mass Spectrometry of Underivatized Oligosaccharides at Low-Femtomole Sensitivity. Anal. Chem. 2004, 76, 833-838.

15. Harvey, D. J. Collision-Induced Fragmentation of Underivatized NLinked Carbohydrates Ionized by Electrospray. J. Mass Spectrom. 2002, 35, 1178-1190.

16. Li, J.; Purves, R. W.; Richards, J. C. Coupling Capillary Electrophoresis and High-Field Asymmetric Waveform Ion Mobility Spectrometry mass Spectrometry for the Analysis of Complex Lipopolysaccharides. Anal. Chem. 2004, 76, 4676-4683.

17. Weiskopf, A. S.; Vouros, P.; Harvey, D. J. Electrospray Ionization-Ion Trap Mass Spectrometry for Structural Analysis of Complex N-Linked Glycoprotein Oligosaccharides. Anal. Chem. 1998, 70, 4441-4447.

18. Harvey, D. J. Ionization and Fragmentation of N-Linked Glycans as Silver Adducts by Electrospray Mass Spectrometry. Rapid Commun. Mass Spectrom. 2005, 19, 484-492.

19. Lattová, E.; Snovida, S.; Perreault, H.; Krokhin, O. Influence of the Labeling Group on Ionization and Fragmentation of Carbohydrates in Mass Spectrometry. J. Am. Soc. Mass Spectrom. 2005, 16, 683-696. 
20. Robbe, C.; Capon, C.; Coddeville, B.; Michalski, J.-C. Diagnostic Ions for the Rapid Analysis by Nano-Electrospray Ionization Quadrupole Timeof-Flight Mass Spectrometry of O-Glycans from Human Mucins. Rapid Commun. Mass Spectrom. 2004, 18, 412-420.

21. Bahr, U.; Pfenninger, A.; Karas, M.; Stahl, B. High-Sensitivity Analysis of Neutral Underivatized Oligosaccharides by Nanoelectrospray Mass Spectrometry. Anal. Chem. 1997, 69, 4530-4535.

22. Gabryelski, W.; Froese, K. L. Rapid and Sensitive Differentiation of Anomers, Linkage, and Position Isomers of Disaccharides Using HighField Asymmetric Waveform Ion Mobility Spectrometry (FAIMS). J. Am. Soc. Mass Spectrom. 2003, 14, 265-277.

23. Clowers, B. H. Dwivedi, P.: Steiner, W. E. Hill, H. H.; Bendiak, B. Separation of Sodiated Isobaric Disaccharides and Trisaccharides Using Electrospray Ionization-Atmospheric Pressure Ion MobilityTime of Flight Mass Spectrometry. J. Am. Soc. Mass Spectrom. 2005, 16, $660-669$.
24. Weiskopf, A. S.; Vouros, P.; Harvey, D. J. Characterization of Oligosaccharide Composition and Structure by Quadrupole Ion Trap Mass Spectrometry. Rapid Commun. Mass Spectrom. 1997, 11, 1493-1504.

25. Sheeley, D. M., Reinhold, V. N. Structural Characterization of Carbohydrate Sequence, Lilnkage, and Branching in a Quadrupole Ion Trap mass Spectrometer: Neutral Oligosaccharides and N-Linked Glycans. Anal. Chem. 1998, 70, 3053-3059.

26. Levin, D. S.; Miller, R. A.; Nazarov, E. G.; Vouros, P. Rapid Separation and Quantitative Analysis of Peptides Using a New NanoelectrosprayDifferential Mobility Spectrometer-Mass Spectrometer System. Anal. Chem. 2006, 78, 5443-5452.

27. Levin, D. S. Vouros, P.; Miller, R. A.; Nazarov, E. G.; Morris, J. C. Characterization of Gas-Phase Molecular Interactions on Differential Mobility Ion Behavior Utilizing an Electrospray Ionization-Differential Mobility-Mass Spectrometer System. Anal. Chem. 2006, 78, $96-$ 106. 